Check for updates

Cite this: RSC Adv., 2017, 7, 35619

\title{
The synergistic effect of cuprous oxide on an intumescent flame-retardant epoxy resin system
}

\author{
Ming-Jun Chen, (D) Xu Wang, Xin-Lei Li, Xing-Ya Liu, Liu Zhong, Hui-Zhen Wang \\ and Zhi-Guo Liu*
}

Neat epoxy resin (EP) is a highly flammable material, and the pyrolysis volatiles of it contain some harmful gases such as carbon monoxide, aromatic compounds, hydrocarbons, etc. Herein, an organic-inorganic hybrid named ethanediamine-modified ammonium polyphosphate (EDA-APP) was used to prepare monocomponent intumescent flame-retardant EP composites. $\mathrm{Cu}_{2} \mathrm{O}$ was used as a synergist for the EP/ EDA-APP system. The fire behavior and smoke emission of EP composites were evaluated by limiting oxygen index (LOI), UL-94 vertical burning, and cone calorimeter test. The results show that the minimum demand of EDA-APP (21 wt\%) is lower than that of APP (25 wt\%) to obtain a UL-94 V-0 rating. In addition, the contents of EDA-APP can be further reduced to $16.3 \mathrm{wt} \%$ to reach UL-94 V-0, and a high $\mathrm{LOI}$ value of $31 \%$ can be obtained only via the addition of extra $1.7 \mathrm{wt} \% \mathrm{Cu}_{2} \mathrm{O}$. Interestingly, the total smoke production (TSP) and carbon monoxide production (COP) are further decreased by loading $\mathrm{Cu}_{2} \mathrm{O}$ onto the EP/EDA-APP composite. Then, the thermal decomposition behavior, morphology, and composition of EP composites and their condensed and gaseous pyrolysis products were analyzed by thermogravimetric analysis (TGA), scanning electron microscopy (SEM), Fourier transform infrared spectroscopy (FTIR), and energy-dispersive X-ray (EDX) spectroscopy, respectively. The test results revealed that the enhancement in flame retardancy and smoke suppression of EP/EDA-APP/ $\mathrm{Cu}_{2} \mathrm{O}$ is due to the synergistic effect and catalytic action of $\mathrm{Cu}_{2} \mathrm{O}$ for accelerating the char formation rate and improving the formation amount, intumescent degree, and compactness of char.

\author{
Received 15th May 2017 \\ Accepted 3rd July 2017 \\ DOI: $10.1039 / \mathrm{c} 7 \mathrm{ra05482c}$ \\ rsc.li/rsc-advances
}

\section{Introduction}

The flammability of epoxy resin (EP) is its potential fire hazard. When it is ignited, the fire rapidly spreads, and great volumes of toxic fumes, such as those of carbon monoxide, aromatic compounds, hydrocarbons, etc. will be concomitantly released. ${ }^{\mathbf{1}, 2}$ This adversely affects human body and environment and also makes firefighting very difficult. ${ }^{3}$ Therefore, it is an urgent social demand to endow EP with good flame retardancy and smoke suppression.

In recent years, ammonium polyphosphate (APP) is one of the most widely used halogen-free flame retardants. This is because it provides both acid and gas sources for the intumescent flame-retardant (IFR) system, and it exhibits excellent flame retarding efficiency for many polymers including EP. ${ }^{4-8}$ However, some shortcomings of APP still exist in its application. APP can hardly perform well as a desirable IFR without a char-forming agent. ${ }^{9}$ Moreover, the compatibility between APP and polymers is not very satisfactory. ${ }^{\mathbf{1 0 , 1 1}}$ To solve these problems, an extra carbonization agent and blowing agent

School of Science (Sichuan), Xihua University, Chengdu 610039, China. E-mail: cmjchem@126.com; liuzg1964@163.com; Fax: +86-28-87720547; Tel: +86-2887720547 were used to cover the shortage of the formation amount and intumescent degree of the char. ${ }^{\mathbf{1 2 - 1 6}}$ Pentaerythritol (PER) and melamine (MEL) are the most commonly used sources of charring and blowing agents, respectively. Surface modification of APP is an effective method to improve its compatibility in the polymer matrix. ${ }^{17-23}$ However, the intumescent char layer of this APP-based IFR system is still not compact and dense; this makes its effect on fire control and smoke reduction less satisfactory. With respect to this issue, ferrocene, ${ }^{\mathbf{1 2}}$ iron oxide brown, ${ }^{23}$ ferrite yellow, ${ }^{24}$ montmorillonite, ${ }^{25,26}$ melamine borate, ${ }^{27}$ boric acid,${ }^{28}$ calcium borate, ${ }^{29}$ titanium oxide, $^{30}$ zinc borate, and diantimony trioxide ${ }^{31}$ were used to enhance the compactness and strength of the intumescent char. In our previous study, it has been found that $\mathrm{Cu}_{2} \mathrm{O}$ exhibits better synergistic effect with epoxy-coated APP than other metal oxides, such as $\mathrm{CuO}, \mathrm{ZnO}, \mathrm{SnO}, \mathrm{Fe}_{2} \mathrm{O}_{3}, \mathrm{Ni}_{2} \mathrm{O}_{3}$, and $\mathrm{Co}_{2} \mathrm{O}_{3}$, on the improvement of flame retardancy and smoke suppression of EP. ${ }^{32}$ This was because $\mathrm{Cu}_{2} \mathrm{O}$ was beneficial for the enhancement of the formation amount, intumescent degree, and compactness of char. The protective layer of intumescent char hindered the decomposition of EP and the diffusion of gaseous products, especially that of toxic gases. In addition, $\mathrm{Cu}_{2} \mathrm{O}$ also played a role in the conversion of $\mathrm{CO}$ to $\mathrm{CO}_{2}$ through a redox cycle. 
In the past three years, note that a novel method for the modification of APP was developed by Wang's group..$^{33-39}$ This method was carried out by a cation exchange reaction between APP and organic amines. A series of APP-based organic-inorganic hybrids was prepared via amine replacement of the part of ammonia. Shao and Wang reported three monocomponent polymeric intumescent flame retardants, which were prepared by modifying APP with ethanediamine (EDA), ethanolamine (ETA), and piperazine (PA). ${ }^{33-35}$ These modified APP exhibited excellent flame-retardant efficiency for polypropylene (PP). This study was further developed by Tan, ${ }^{36-38}$ and diethylenetriamine- and polyethyleneimine-modified APP were prepared as multifunctional flame-retardant curing agents for EP. These curing agents not only improved the flame retardancy of EP, but also reduced the smoke emission. However, the curing temperature and time were higher than those needed in the common curing system ${ }^{\mathbf{4 0 - 4 5}}$ such as those involving 4,4'-diamino diphenyl methane (DDM) and polyamide (PA).

This study was conducted to explore whether the organic amine-modified APP acted as an additive type flame retardant and had a synergistic effect with $\mathrm{Cu}_{2} \mathrm{O}$ on enhancing the flame retardancy and reducing the smoke release of EP. Herein, low molecular weight polyamide was chosen as the curing agent for EP, and ethanediamine-modified ammonium polyphosphate (EDA-APP) was used to build the monocomponent intumescent flame-retardant system. The contribution of EDA-APP to flame retardancy and smoke suppression was compared with that of APP, and the synergistic effect between EDA-APP and $\mathrm{Cu}_{2} \mathrm{O}$ was investigated. In addition, the flame-retardant and smokesuppressant mechanisms of $\mathrm{EP} / \mathrm{EDA}-\mathrm{APP} / \mathrm{Cu}_{2} \mathrm{O}$ composite were proposed by analyzing the gaseous and condensed pyrolysis products in detail.

\section{Experimental}

\subsection{Materials}

Bisphenol A epoxy with an epoxide equivalent of $5.1 \mathrm{~mol} \mathrm{~kg}^{-1}$ (commercial name E-51) was purchased from Nantong Xingchen Synthetic Material Co., Ltd., China. Although polyamide has the limitation of low heat resistance, it is still favorable to be used as a curing agent for epoxy because of its low toxicity, good compatibility, and toughening effect. Commercial polyamide (PA650) was obtained from Xiangtan Hongsang Viscose Materials Co., Ltd., China. The organic silicone antifoaming agent (AT86S) was supplied by Datian Chemical Co., Ltd., China. Commercial ammonium polyphosphate (APP, form II) was supplied by Shifang Taifeng New Flame Retardant Co., Ltd., China. Cuprous oxide $\left(\mathrm{Cu}_{2} \mathrm{O}\right)$ and ethanediamine (EDA) were of analytical reagent grade and purchased from Chengdu Kelong Chemical Regent Factory, China.

\subsection{Preparation of the epoxy composites}

First, EDA-APP was prepared according to the previous research of Shao, ${ }^{34}$ and the amount of EDA loaded into EDA-APP was about $4 \%$. The chemical structure of EDA-APP is shown in Scheme 1. EDA-APP and $\mathrm{Cu}_{2} \mathrm{O}$ were dried in a vacuum oven at

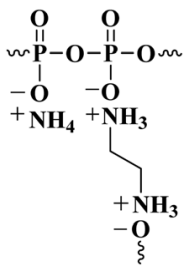

Scheme 1 The chemical structure of EDA-APP.

$80{ }^{\circ} \mathrm{C}$ for $6 \mathrm{~h}$ before use. Then, E51, PA650 (curing agent), AT86S (antifoaming agent), EDA-APP (intumescent flame retardant), and $\mathrm{Cu}_{2} \mathrm{O}$ (synergistic agent) were stirred at $60{ }^{\circ} \mathrm{C}$ until they were well blended. The mixture was then poured into preheated molds and cured at $120{ }^{\circ} \mathrm{C}$ for $2 \mathrm{~h}$. The formulations of EP thermosets are listed in Table 1.

\subsection{Measurements}

Limiting oxygen index (LOI) value was determined at room temperature using a Jiangning JF-3 oxygen index instrument (China) according to ASTM D2863-97. The size of the specimen was $130 \mathrm{~mm} \times 6.5 \mathrm{~mm} \times 3.2 \mathrm{~mm}$.

The UL-94 vertical burning test was performed using a Jiangning CZF-3 instrument (China) according to ASTM D3801. The dimension of the sample was $130 \mathrm{~mm} \times 12.7 \mathrm{~mm} \times 3.2 \mathrm{~mm}$.

The flammability of the sample was measured by a FTT cone calorimeter instrument (UK) under a heat flux of $35 \mathrm{~kW} \mathrm{~m}^{-2}$ according to ISO 5660-1. The size of the specimen was $100 \mathrm{~mm}$ $\times 100 \mathrm{~mm} \times 3 \mathrm{~mm}$.

Thermogravimetric analysis (TGA) was performed using a Perkin-Elmer STA6000 instrument (UK). The sample (6-8 mg) was heated to $700{ }^{\circ} \mathrm{C}$ at a heating rate of $10{ }^{\circ} \mathrm{C} \mathrm{min}^{-1}$ under

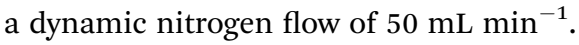

Fourier transform infrared spectroscopy (FTIR) of the samples was performed using a Nicolet 380 spectrometer (US) in the wavenumber range from 500 to $4000 \mathrm{~cm}^{-1}$ using $\mathrm{KBr}$ pellets.

The gases evolved during the TGA tests were analyzed by coupling TG with FTIR. TGA and FTIR were performed using Perkin-Elmer STA6000 and FRONTIER instrument (UK), respectively. The samples were heated to $700{ }^{\circ} \mathrm{C}$ at a heating rate of $10{ }^{\circ} \mathrm{C} \mathrm{min}{ }^{-1}$ under a dynamic nitrogen flow of $50 \mathrm{~mL} \mathrm{~min}{ }^{-1}$.

The morphology of the char layers was observed by scanning electron microscopy (SEM). SEM images were obtained by an INSPECT F scanning electron microscope (US) at the accelerating voltage of $20 \mathrm{kV}$. The surfaces were coated with a thin gold layer before observation.

The phosphorus and copper contents of external and internal char layer were detected by energy-dispersive X-ray (EDX) spectroscopy (INCA, Oxford Instruments, Abingdon, Oxfordshire, U.K.).

\section{Results and discussion}

\subsection{Fire performance}

The flame retardancy of the epoxy composites was evaluated via LOI and UL-94 vertical burning tests, and the corresponding 
Table 1 The formulations and flammability test (LOI and UL-94) data of epoxy composites

\begin{tabular}{|c|c|c|c|c|c|c|c|c|}
\hline Sample & E51 (wt\%) & $\begin{array}{l}\text { PA } 650 \\
\text { (wt } \%)\end{array}$ & $\begin{array}{l}\text { AT86S } \\
\text { (wt\%) }\end{array}$ & $\begin{array}{l}\text { EDA-APP } \\
(\mathrm{wt} \%)\end{array}$ & APP (wt\%) & $\begin{array}{l}\mathrm{Cu}_{2} \mathrm{O} \\
(\mathrm{wt} \%)\end{array}$ & UL-94 & LOI $(\%)$ \\
\hline Neat EP & 55.28 & 44.22 & 0.50 & & & & NR & 20.0 \\
\hline $\mathrm{EP} / \mathrm{APP}_{21 \%}$ & 43.61 & 34.89 & 0.50 & & 21.00 & & NR & 33.0 \\
\hline $\mathrm{EP} / \mathrm{Cu}_{2} \mathrm{O}_{21 \%}$ & 43.61 & 34.89 & 0.50 & & & 21.00 & NR & 22.0 \\
\hline EP/EDA-APP $21 \%$ & 43.61 & 34.89 & 0.50 & 21.00 & & & V-0 & 33.0 \\
\hline EP/EDA-APP $18 \% / \mathrm{Cu}_{2} \mathrm{O}_{3 \%}$ & 43.61 & 34.89 & 0.50 & 18.00 & & 3.00 & V-0 & 33.5 \\
\hline EP/EDA-APP $17 \% / \mathrm{Cu}_{2} \mathrm{O}_{4 \%}$ & 43.61 & 34.89 & 0.50 & 17.00 & & 4.00 & $\mathrm{~V}-1$ & 32.5 \\
\hline EP/EDA-APP ${ }_{16.3 \%} / \mathrm{Cu}_{2} \mathrm{O}_{1.7 \%}$ & 45.28 & 36.22 & 0.50 & 16.29 & & 1.71 & $\mathrm{~V}-0$ & 31.0 \\
\hline EP/EDA-APP $15.4 \% / \mathrm{Cu}_{2} \mathrm{O}_{1.6 \%}$ & 45.83 & 36.67 & 0.50 & 15.38 & & 1.62 & V-1 & 30.5 \\
\hline
\end{tabular}

data are summarized in Table 1. It illustrated that neat EP was a very flammable material because of its low LOI value $(20 \%)$ and fast fire spread. The LOI value of EP can be improved to a certain extent via the incorporation of $\mathrm{APP}, \mathrm{Cu}_{2} \mathrm{O}$, and EDAAPP. In addition, the highest UL-94 rating of V-0 can be reached through the introduction of APP and EDA-APP. However, to obtain V-0, the minimum demand for EDA-APP (21 wt $\%)$ was lower than that for APP (25 wt $\%)$. This indicated that EDA-APP was more effective than APP for enhancing the flame resistance of EP. To further improve the flame-retardant efficiency of EDA-APP, extra $\mathrm{Cu}_{2} \mathrm{O}$ was added. The best mass ratio of EDA-APP to $\mathrm{Cu}_{2} \mathrm{O}$ was determined to be $19: 2$ because $\mathrm{EP} / \mathrm{EDA}-\mathrm{APP}_{19 \%} / \mathrm{Cu}_{2} \mathrm{O}_{2} \%$ reached the highest LOI value of $33.5 \%$ and UL-94 rating of V-0. On controlling this mass ratio, the contents of EDA-APP can be further reduced to $16.3 \mathrm{wt} \%$ to reach $\mathrm{V}-0$ and also to obtain the high LOI value of $31 \%$. This indicated that $\mathrm{Cu}_{2} \mathrm{O}$ had good synergistic effect with EDA-APP for the enhancement of the flame retardancy of EP.

Cone calorimeter measurement is one of the most effective methods for assessing the fire behavior of materials. Herein, it was used to analyze the flame retardancy, smoke suppression, and toxicity reduction of the flame-retardant EP composites. The heat release rate (HRR) and total heat release (THR) curves of neat $\mathrm{EP}, \mathrm{EP} / \mathrm{APP}_{21 \%}, \mathrm{EP} / \mathrm{EDA}-\mathrm{APP}_{21 \%}, \mathrm{EP} / \mathrm{Cu}_{2} \mathrm{O}_{21 \%}$, and $\mathrm{EP} /$ EDA-APP ${ }_{19 \%} / \mathrm{Cu}_{2} \mathrm{O}_{2 \%}$ are shown in Fig. 1 . The corresponding data obtained from cone calorimetry are presented in Table 2 . From Fig. 1, it can be seen that both the HRR and THR of EP composites were obviously reduced via the addition of any kind of additives (APP, EDA-APP, and $\mathrm{Cu}_{2} \mathrm{O}$ ) as compared to those of neat EP. In Table 2, note that the contribution of EDA-APP was much better than that of APP towards the reduction of the peak of the heat release rate (PHRR) for EP. In addition, EDA-APP also exhibited better performance than APP on increasing the time to ignition (TTI) and time to PHRR $\left(t_{\mathrm{P}}\right)$, as well as on decreasing the average heat release rate (AvHRR), fire growth rate (FIGRA), and maximum average rate of heat emission (MARHE). This illustrated that the fire risk of the EP/EDA-APP ${ }_{21 \%}$ system was greatly lower than that of the $\mathrm{EP} / \mathrm{APP}_{21 \%}$ system. With the purpose of further improving the flame retardancy of the EP/ EDA-APP system, $\mathrm{Cu}_{2} \mathrm{O}$ was added to it. The results showed that the PHRR and AvHRR of EP/EDA-APP ${ }_{19 \%} / \mathrm{Cu}_{2} \mathrm{O}_{2 \%}$ were declined by about $68 \%$ and $61 \%$, i.e. to $364 \mathrm{~kW} \mathrm{~m}^{-2}$ and $65 \mathrm{~kW}$ $\mathrm{m}^{-2}$, respectively, only via the addition of extra $2 \mathrm{wt} \% \mathrm{Cu}_{2} \mathrm{O}$. Moreover, the compactness of the char layer was obviously enhanced by $\mathrm{Cu}_{2} \mathrm{O}$ because of the absence of holes and cracks, as shown in Fig. 2 .

\subsection{Suppression of the smoke and toxic gases}

It has been reported that most fire deaths are due to smoke inhalation, oxygen deprivation, and toxic gases instead of
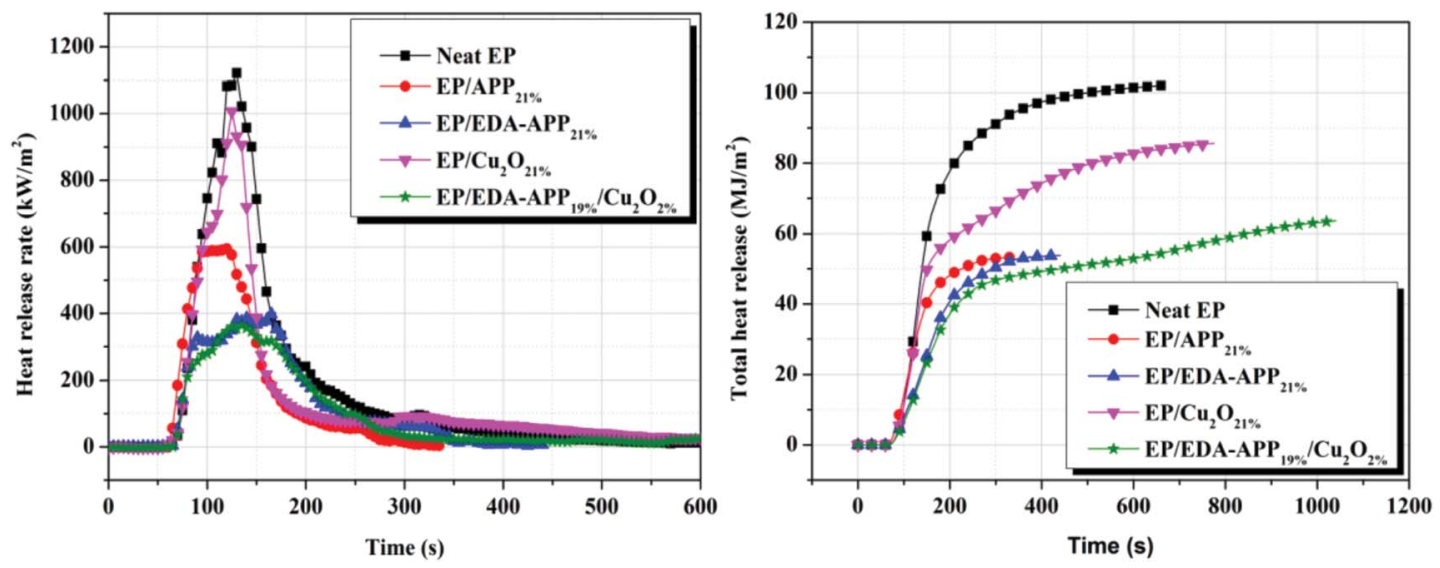

Fig. 1 The heat release rate and total heat release curves of neat $\mathrm{EP}, \mathrm{EP} / \mathrm{APP}_{21 \%}, \mathrm{EP} / \mathrm{EDA}-\mathrm{APP} 21 \%, \mathrm{EP} / \mathrm{Cu}_{2} \mathrm{O}_{21 \%}, \mathrm{and}_{\mathrm{EP} / E D A}-\mathrm{APP} \mathrm{P}_{19 \%} / \mathrm{Cu}_{2} \mathrm{O}_{2 \%}$. 
Table 2 The data of cone calorimeter test on neat EP and EP composites with 21 wt\% of flame retardants ${ }^{a}$

\begin{tabular}{|c|c|c|c|c|c|c|c|}
\hline Sample & TTI (s) & $\begin{array}{l}\text { PHRR } \\
\left(\mathrm{kW} \mathrm{m}^{-2}\right)\end{array}$ & $\begin{array}{l}\text { AvHRR } \\
\left(\mathrm{kW} \mathrm{m}^{-2}\right)\end{array}$ & $t_{\mathrm{P}}(\mathrm{s})$ & FIGRA & $\begin{array}{l}\text { THR } \\
\left(\mathrm{MJ} \mathrm{m}^{-2}\right)\end{array}$ & $\begin{array}{l}\text { MARHE } \\
\left(\mathrm{kW} \mathrm{m}^{-2}\right)\end{array}$ \\
\hline Neat EP & 53 & 1121 & 167 & 130 & 8.62 & 102 & 408 \\
\hline EP/EDA-APP $21 \%$ & 61 & 398 & 144 & 165 & 2.40 & 54 & 203 \\
\hline $\mathrm{EP} / \mathrm{Cu}_{2} \mathrm{O}_{21 \%}$ & 47 & 1007 & 118 & 125 & 8.06 & 86 & 331 \\
\hline EP/EDA-APP ${ }_{19 \%} / \mathrm{Cu}_{2} \mathrm{O}_{2} \%$ & 62 & 364 & 65 & 135 & 2.70 & 64 & 186 \\
\hline
\end{tabular}

${ }^{a}$ TTI means time to ignition, PHRR represents the peak of heat release rate, AvHRR is the average heat release rate, $t_{\mathrm{P}}$ denotes time to PHRR, FIGRA is calculated by dividing the PHRR by $t_{\mathrm{P}}$, THR represents total heat release, and MARHE denotes the maximum average rate of heat emission.

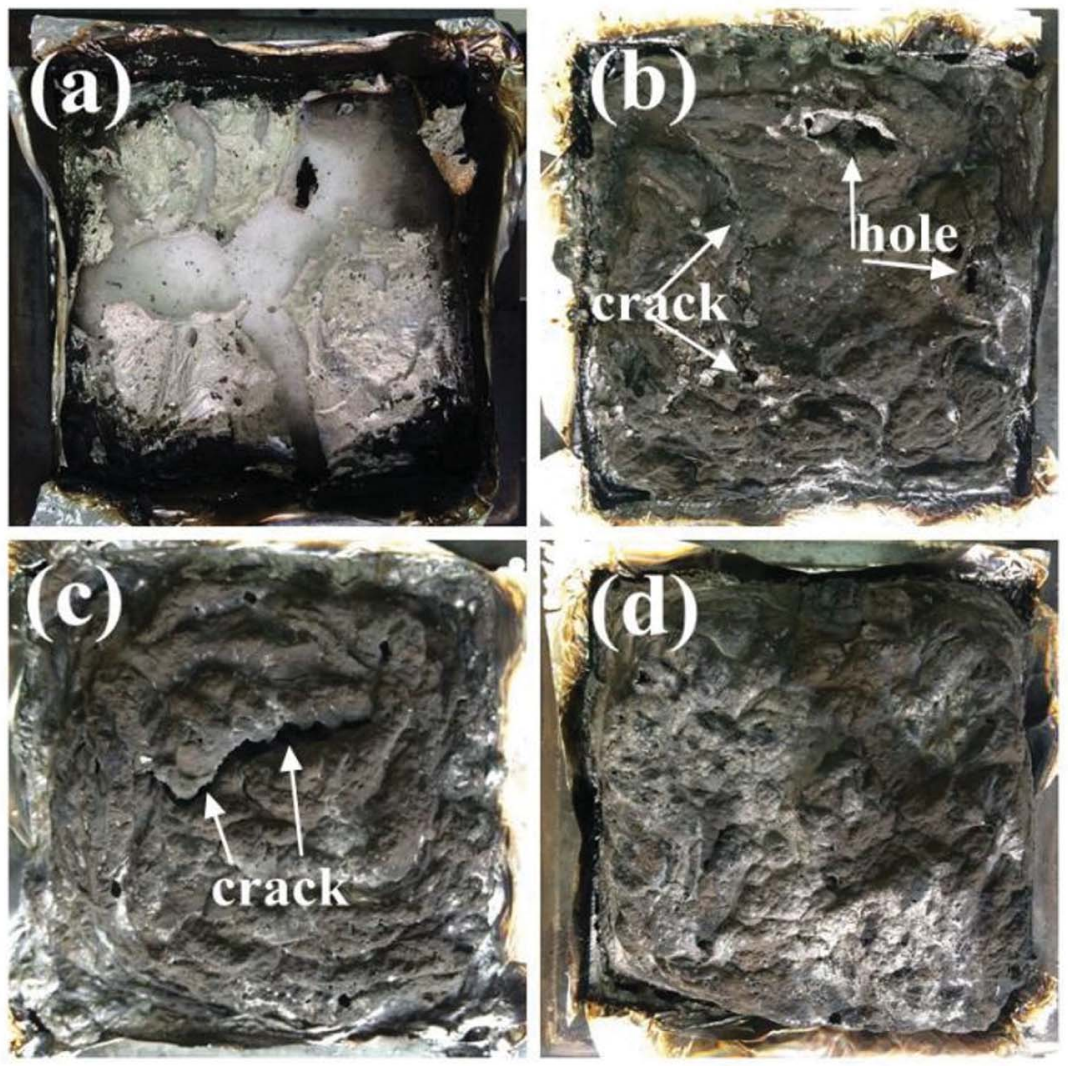

Fig. 2 The images for char residues of neat EP (a), EP/APP $21 \%$ (b), EP/EDA-APP $21 \%$ (c), and EP/EDA-APP $19 \% / \mathrm{Cu}_{2} \mathrm{O}_{2 \%}(\mathrm{~d})$ after cone calorimeter test.

burns. ${ }^{3}$ The disadvantages of EP are not only its high flammability, but also the large amount of dense smoke and toxic gases generated during its combustion. Obviously, smoke production rate (SPR), total smoke production (TSP), and CO production (COP) are important parameters for assessing the fire hazard of EP. It can be observed from Fig. 3 that the SPR of EP/EDA$\mathrm{APP}_{21 \%}$ was lower than that of $\mathrm{EP} / \mathrm{APP}_{21 \%}$, and the addition of $\mathrm{Cu}_{2} \mathrm{O}$ further reduced the SPR and TSP of the EP/EDA-APP composite. Furthermore, the $\mathrm{CO}$ production $(\mathrm{COP})$ and $\mathrm{CO}_{2}$ production $\left(\mathrm{CO}_{2} \mathrm{P}\right)$ were also decreased upon the loading of $\mathrm{Cu}_{2} \mathrm{O}$ into the EP/EDA-APP composite, as shown in Fig. 4. Especially, the COP of EP/EDA-APP ${ }_{19 \%} / \mathrm{Cu}_{2} \mathrm{O}_{2} \%$ was lessened by $53 \%$ as compared to that of neat EP. It was probably due to the enhancement of the char formation amount and the intumescent degree caused by $\mathrm{Cu}_{2} \mathrm{O}$, as well as the catalytic oxidation action of $\mathrm{Cu}_{2} \mathrm{O}$ on $\mathrm{CO}$.

To further understand the composition of the smoke, TG coupled with FTIR (TG-FTIR) was used to determine the pyrolysis products of neat $\mathrm{EP}, \mathrm{EP} / \mathrm{APP}_{21 \%}$, and $\mathrm{EP} / \mathrm{EDA}-\mathrm{APP}_{21 \%}$. The absorbance of four characteristic gaseous products, i.e. ammonia $\left(\mathrm{NH}_{3}\right)$, hydrocarbons, aromatic compounds, and epoxy derivatives, are shown in Fig. 5. It can be seen that the addition of APP and EDA-APP caused the increase of $\mathrm{NH}_{3}$, but decrease of hydrocarbons, aromatic compounds, and epoxy derivatives. In addition, more $\mathrm{NH}_{3}$ was released from EP/ $\mathrm{APP}_{21 \%}$ than EP/EDA-APP ${ }_{21 \%}$. However, EP/EDA-APP ${ }_{21 \%}$ was better than $\mathrm{EP} / \mathrm{APP}_{21 \%}$ in restraining the production of hydrocarbons, aromatic compounds, and epoxy derivatives. This is 

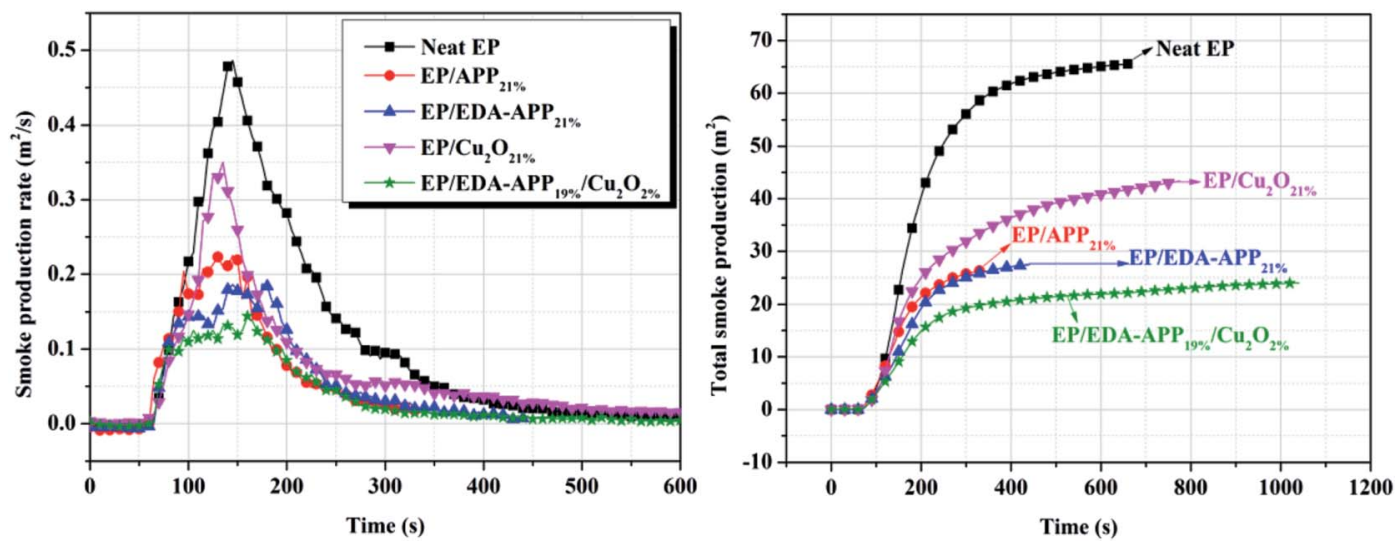

Fig. 3 The smoke production rate and total smoke production curves of neat EP, EP/APP $21 \%, E P / E D A-A P P_{21 \%}, E^{2} / C_{2} \mathrm{O}_{21 \%}$, and EP/EDA-APP $19 \% /$ $\mathrm{Cu}_{2} \mathrm{O}_{2} \%$.
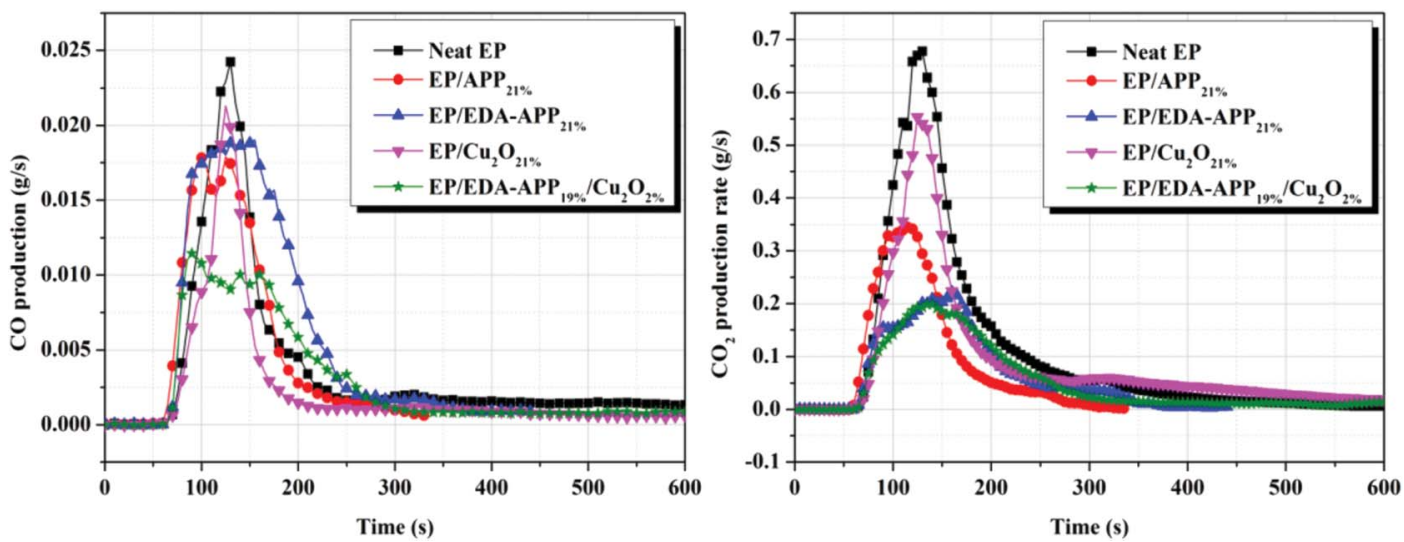

Fig. 4 The $\mathrm{CO}$ and $\mathrm{CO}_{2}$ production curves of neat $\mathrm{EP}, \mathrm{EP} / \mathrm{APP} 21 \%, \mathrm{EP} / \mathrm{EDA}-\mathrm{APP}_{21 \%}, \mathrm{EP} / \mathrm{Cu}_{2} \mathrm{O}_{21 \%}$, and $\mathrm{EP} / \mathrm{EDA}_{2}-\mathrm{APP}_{19 \%} / \mathrm{Cu}_{2} \mathrm{O}_{2 \%}$.

due to the fact that an ammonium group of EDA-APP was substituted by ethanediamine; this led to the reduction of $\mathrm{NH}_{3}$, but improvement of the char formation rate for $\mathrm{EP} / \mathrm{EDA}-\mathrm{APP}_{21 \%}$. The initially formed intumescent char was in favor of hindering the decomposition of EP and suppressing the release of smoke and toxic gases.

\subsection{Thermal degradation analysis}

The thermal degradation behaviors of APP, EDA-APP, neat EP, and EP composites with $21 \mathrm{wt} \%$ of flame retardants (APP, EDAAPP, and $\mathrm{Cu}_{2} \mathrm{O}$ ) were investigated by TGA. The TG and DTG curves of them are presented in Fig. 6 , and the main results are summarized in Table 3. It can be observed from Fig. 6 that both APP and EDA-APP contain two weak (300-450 $\left.{ }^{\circ} \mathrm{C}\right)$ and one strong $\left(450-650{ }^{\circ} \mathrm{C}\right)$ weight loss processes. The degradation in the range of $300-450{ }^{\circ} \mathrm{C}$ was mainly due to the elimination of $\mathrm{NH}_{3}$ and $\mathrm{H}_{2} \mathrm{O}$, and the weight loss at $450-650{ }^{\circ} \mathrm{C}$ was attributed to the pyrolysis of phosphoric acid and its derivatives. ${ }^{46}$ The weight loss rate of EDA-APP was lower than that of APP before $620{ }^{\circ} \mathrm{C}$ but became higher after $620^{\circ} \mathrm{C}$. The reason was that the $\mathrm{C}-\mathrm{N}\left(305 \mathrm{~kJ} \mathrm{~mol}^{-1}\right)$ bond of ethanediamine salt $\left(\mathrm{NH}_{3}{ }^{+}-\mathrm{CH}_{2}-\right.$ $\mathrm{CH}_{2}-\mathrm{NH}_{3}{ }^{+}$) in EDA-APP was less stable than the P-O (335 kJ $\mathrm{mol}^{-1}$ ) bond in APP. ${ }^{36,47}$ This also caused the decrease in the initial degradation temperature $\left(T_{5} \%\right.$ of EDA-APP. The early decomposition of EDA-APP helped in the generation of phosphoric acid and its derivatives in advance that acted as dehydrating agents for carbonization. Thus, EDA-APP produced a stable char residue earlier than APP, and as a result, more char residue was formed. Moreover, these phosphoric acid derivatives generated from EDA-APP promoted the dehydration of EP and the formation of protective char earlier than APP. This was the reason for the lower weight loss rate of $\mathrm{EP} / \mathrm{EDA}-\mathrm{APP}_{21 \%}$ than that of $\mathrm{EP} / \mathrm{APP}_{21 \%}$ in the range of $300-400{ }^{\circ} \mathrm{C}$. When $\mathrm{Cu}_{2} \mathrm{O}$ was added to the EP/EDA-APP system, the decomposition of EP was accelerated, and the char residue was improved.

\subsection{Flame-retardant and smoke-suppressant mechanisms}

To evaluate how EDA-APP worked on improving the flame retardancy of EP and how EDA-APP/ $/ \mathrm{Cu}_{2} \mathrm{O}$ acted on suppressing the release of smoke and toxic gases, the condensed phase and gaseous phase pyrolysis products of EDA-APP were investigated by FTIR (Fig. 7). The condensed phase decomposition products of EDA-APP were obtained in a muffle furnace. The gaseous products of EDA-APP, neat EP, and EP/EDA-APP $21 \%$ evolved 

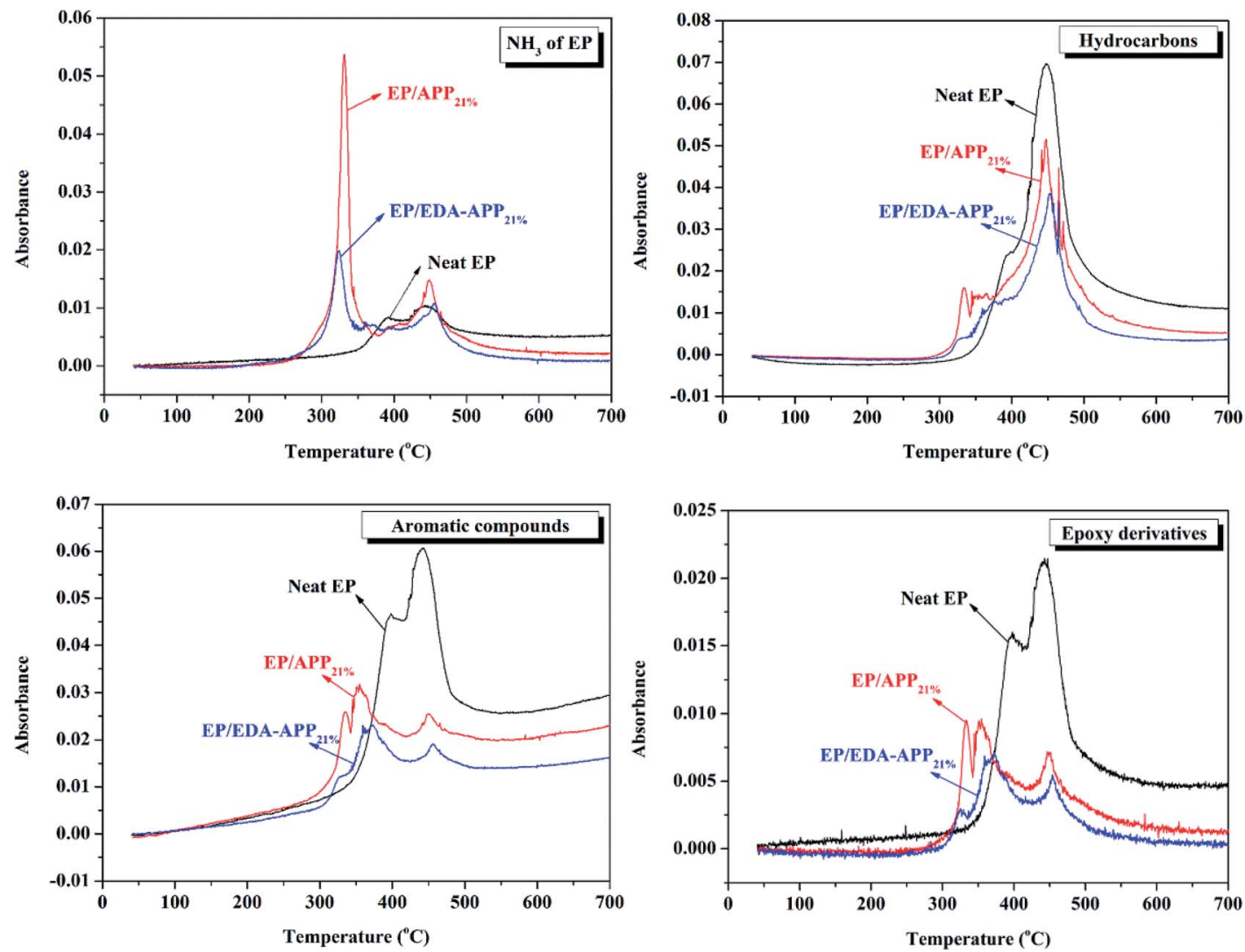

Fig. 5 Intensity of characteristic peaks for $\mathrm{NH}_{3}$, hydrocarbons, aromatic compounds, and epoxy derivatives pyrolysised from $\mathrm{Neat}$ EP, EP/APP $21 \%$, and EP/EDA-APP $21 \%$.
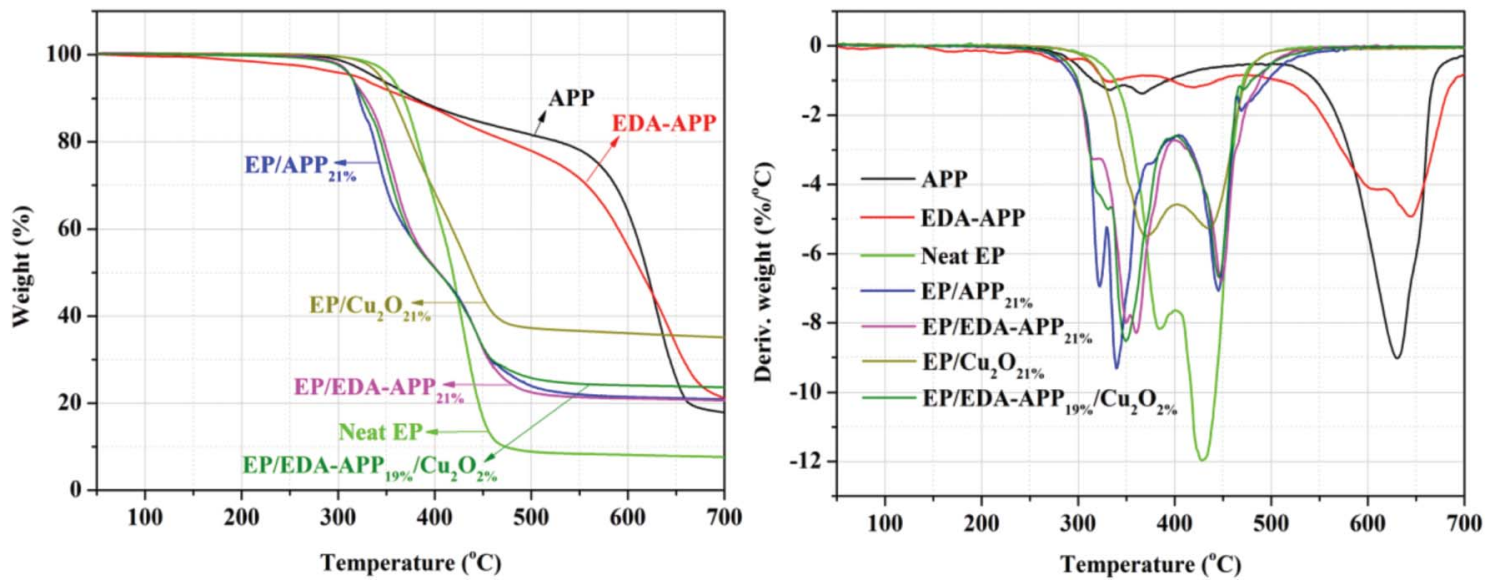

Fig. 6 TG and DTG curves of APP, EDA-APP, neat EP, and EP composites with $21 \mathrm{wt} \%$ of flame retardants at the heating rate of $10{ }^{\circ} \mathrm{C}$ min ${ }^{-1}$ in $\mathrm{N}_{2}$.

during TGA tests were analyzed by coupling TG with FTIR, as shown in Fig. 7 and 8. The microstructure and composition of the chars of EP/EDA-APP ${ }_{19 \%} / \mathrm{Cu}_{2} \mathrm{O}_{2 \%}$ after the cone calorimeter test were examined by SEM and EDX (Fig. 9).

From Fig. 7, it can be observed that $\mathrm{NH}_{2}$ group (3435, 3336 $\left.\mathrm{cm}^{-1}\right), \mathrm{NH}_{3}^{+}$group (3201 $\left.\mathrm{cm}^{-1}\right), \mathrm{NH}_{4}{ }^{+}$group $\left(3126 \mathrm{~cm}^{-1}\right), \mathrm{CH}_{2}$ group $\left(2921,2852 \mathrm{~cm}^{-1}\right), \mathrm{P}=\mathrm{O}$ group $\left(1250 \mathrm{~cm}^{-1}\right)$, and $\mathrm{P}-\mathrm{O}$ group $\left(1069 \mathrm{~cm}^{-1}\right)$ existed in EDA-APP. With the beginning of decomposition, the $\mathrm{NH}_{2}$ and $\mathrm{NH}_{3}{ }^{+}$groups broke at about $315{ }^{\circ} \mathrm{C}$, the $\mathrm{NH}_{4}{ }^{+}, \mathrm{P}=\mathrm{O}$, and $\mathrm{P}-\mathrm{O}$ groups were gradually weakened before $420{ }^{\circ} \mathrm{C}$, and the concomitant products were $\mathrm{NH}_{3}$ (964 and $\left.930 \mathrm{~cm}^{-1}\right), \mathrm{H}_{2} \mathrm{O}\left(3126 \mathrm{~cm}^{-1}\right)$, and a small amount of gases containing $\mathrm{P}=\mathrm{O}\left(1249 \mathrm{~cm}^{-1}\right), \mathrm{P}-\mathrm{H}\left(2362 \mathrm{~cm}^{-1}\right), \mathrm{C}=\mathrm{C}$ $\left(1629 \mathrm{~cm}^{-1}\right)$, and $\mathrm{C} \equiv \mathrm{N}\left(2240 \mathrm{~cm}^{-1}\right)$ groups. At a higher temperature $\left(644{ }^{\circ} \mathrm{C}\right), \mathrm{NH}_{4}{ }^{+}$was ruptured absolutely and there was no $\mathrm{NH}_{3}$ emission. However, a stable char residue with $\mathrm{C}=\mathrm{C}$ 
Table 3 TGA data of APP, EDA-APP, neat EP, and EP composites with $21 \mathrm{wt} \%$ of flame retardants at the heating rate of $10{ }^{\circ} \mathrm{C} \mathrm{min}{ }^{-1}$ in $\mathrm{N}_{2}$

\begin{tabular}{|c|c|c|c|c|c|}
\hline Sample & $T_{5 \%}{ }^{a}\left({ }^{\circ} \mathrm{C}\right)$ & $T_{\max 1}^{b}\left({ }^{\circ} \mathrm{C}\right)$ & $T_{\max 2}\left({ }^{\circ} \mathrm{C}\right)$ & $T_{\max 3}\left({ }^{\circ} \mathrm{C}\right)$ & $\mathrm{wt}_{\mathrm{R}}^{700 c}(\%)$ \\
\hline APP & 336 & 332 & 365 & 630 & 18 \\
\hline EDA-APP & 315 & 334 & 420 & 644 & 21 \\
\hline $\mathrm{EP} / \mathrm{APP}_{21 \%}$ & 312 & 321 & 339 & 444 & 21 \\
\hline EP/EDA-APP $21 \%$ & 311 & 359 & 447 & & 20 \\
\hline $\mathrm{EP} / \mathrm{Cu}_{2} \mathrm{O}_{21} \%$ & 343 & 369 & 434 & & 35 \\
\hline
\end{tabular}

${ }^{a} T_{5 \%}$ denotes the temperature at $5 \%$ weight loss. ${ }^{b} T_{\max 1}$ denotes the temperature at the first maximum weight loss. ${ }^{c}$ wt $\mathrm{R}_{\mathrm{R}}^{700}$ denotes the weight of char residue at $700{ }^{\circ} \mathrm{C}$.

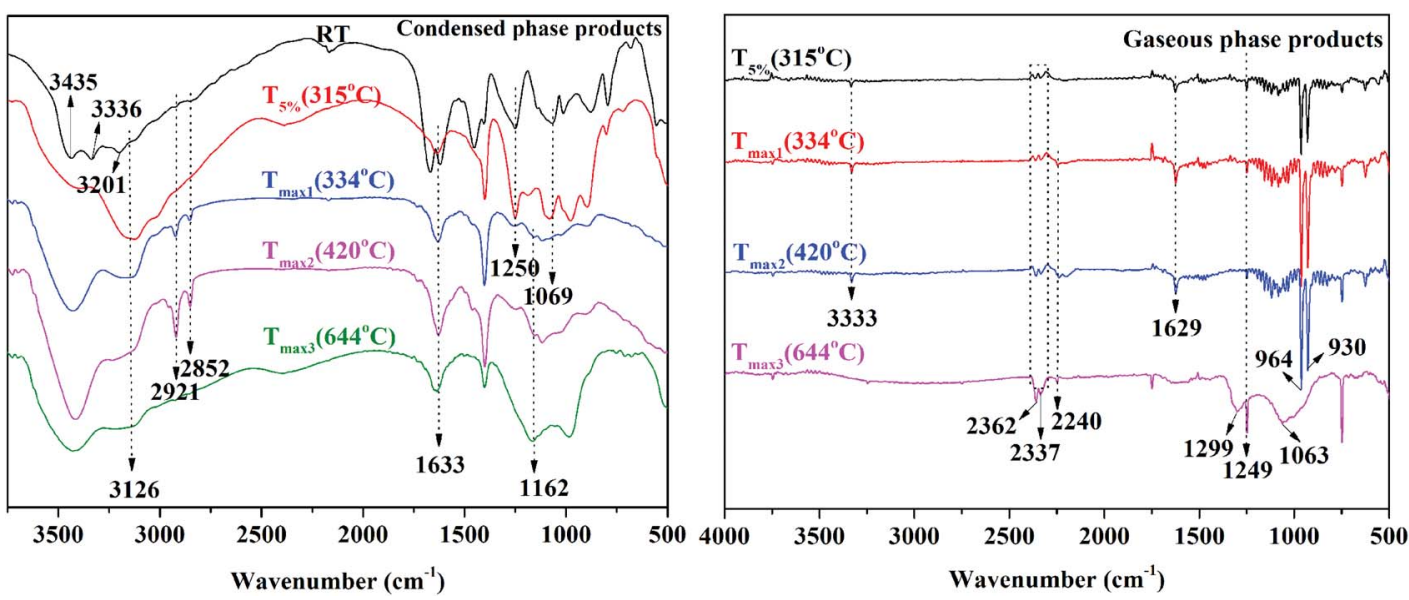

Fig. 7 The FTIR spectra of condensed and gaseous phase pyrolysis products of EDA-APP at different temperatures.

or $\mathrm{C}=\mathrm{N}\left(1633 \mathrm{~cm}^{-1}\right)$ and $\mathrm{P}-\mathrm{N}-\mathrm{C}$ group $\left(1162 \mathrm{~cm}^{-1}\right)$ was formed; moreover, the gases containing the $\mathrm{P}=\mathrm{O}, \mathrm{P}-\mathrm{O}\left(1063 \mathrm{~cm}^{-1}\right)$, and $\mathrm{P}-\mathrm{H}$ groups were increased. It indicated that the elimination of $\mathrm{NH}_{3}$ and $\mathrm{H}_{2} \mathrm{O}$ mainly occurred before $420{ }^{\circ} \mathrm{C}$, and the majority of phosphoric acid and its derivatives were produced after this temperature.

Fig. 8 shows the FTIR spectra of gaseous products of neat EP and EP/EDA-APP $21 \%$. A large amount of harmful gases containing aromatic compounds ( 3015 and $1508 \mathrm{~cm}^{-1}$ ), hydrocarbons $\left(2973,2935\right.$, and $\left.2878 \mathrm{~cm}^{-1}\right)$, and epoxy derivatives (827, $749 \mathrm{~cm}^{-1}$ ) were diffused during the decomposition of neat EP. The loading of EDA-APP caused the enhancement of the peaks at 2360 and $2230 \mathrm{~cm}^{-1}$; moreover, a lot of $\mathrm{NH}_{3}$ was generated at 964 and $930 \mathrm{~cm}^{-1}$. This was due to the stretching vibration of some gases containing $\mathrm{P}-\mathrm{H}$ group that appeared near 2360 $\mathrm{cm}^{-1}$. The generation of $\mathrm{NH}_{3}$ was derived from EDA-APP.

The morphology and composition of the external and internal chars of EP/EDA-APP ${ }_{19 \%} / \mathrm{Cu}_{2} \mathrm{O}_{2 \%}$ are shown in Fig. 9. The external char layer was so compact and dense (Fig. 9(a) and (b)) that it effectively hindered the transmission of heat and oxygen from the flame zone to the surface of the material. A swollen char layer (Fig. 9(c) and (d)) was formed on the internal surface, which effectively prevented the inside pyrolysis products from transmitting into the flame zone. The elements such as carbon $(\mathrm{C})$, nitrogen $(\mathrm{N})$, oxygen $(\mathrm{O})$, phosphorus $(\mathrm{P})$, and copper $(\mathrm{Cu})$ were found in the external and internal char layer (Fig. 9(e) and (f)), and their average weight percentage were found to be $39.06 \mathrm{wt} \%, 42.72 \mathrm{wt} \%, 12.83 \mathrm{wt} \%$, $3.38 \mathrm{wt} \%$, and $2.01 \mathrm{wt} \%$, respectively. Interestingly, the nitrogen content of the external char layer was higher than that of the internal char layer; on the contrary, the phosphorus content of the internal char layer was higher. It illustrated that the external char surface was mainly composed of the nitrogen-containing stable char layer, and the phosphorusrich char mainly remained on the internal surface. This intumescent char layer was composed of products containing alkyl groups (2918 and $2855 \mathrm{~cm}^{-1}$ ) $\mathrm{C}=\mathrm{C}, \mathrm{C}=\mathrm{N}, \mathrm{N}=\mathrm{N}$, and aryl groups $\left(1633 \mathrm{~cm}^{-1}\right), \mathrm{P}=\mathrm{O}$ group $\left(1262 \mathrm{~cm}^{-1}\right), \mathrm{P}-\mathrm{N}-\mathrm{C}$ group $\left(1144 \mathrm{~cm}^{-1}\right)$, and $\mathrm{P}-\mathrm{O}$ group $\left(1080 \mathrm{~cm}^{-1}\right)$, as shown in Fig. $9(\mathrm{~g})$. $\mathrm{Cu}_{2} \mathrm{O}$ in the EP/EDA-APP composite was finally oxidized to $\mathrm{CuO}$, which was uniformly dispersed in the char and acted as a good synergist for enhancing the compactness of the EP/ EDA-APP char residue. The most possible constituents and the corresponding element contents of char residue are listed in Table 4.

On combining the abovementioned results with the reported findings, ${ }^{34,37,38}$ the possible flame-retardant and smokesuppressant mechanisms are proposed in Scheme 2 . The early decomposition of EDA-APP caused the generation of phosphoric acid and its derivatives in advance (before $450{ }^{\circ} \mathrm{C}$ ), which was beneficial to promote the dehydration of $\mathrm{EP}$ and the earlier formation of protective char. In addition, $\mathrm{Cu}_{2} \mathrm{O}$ further 

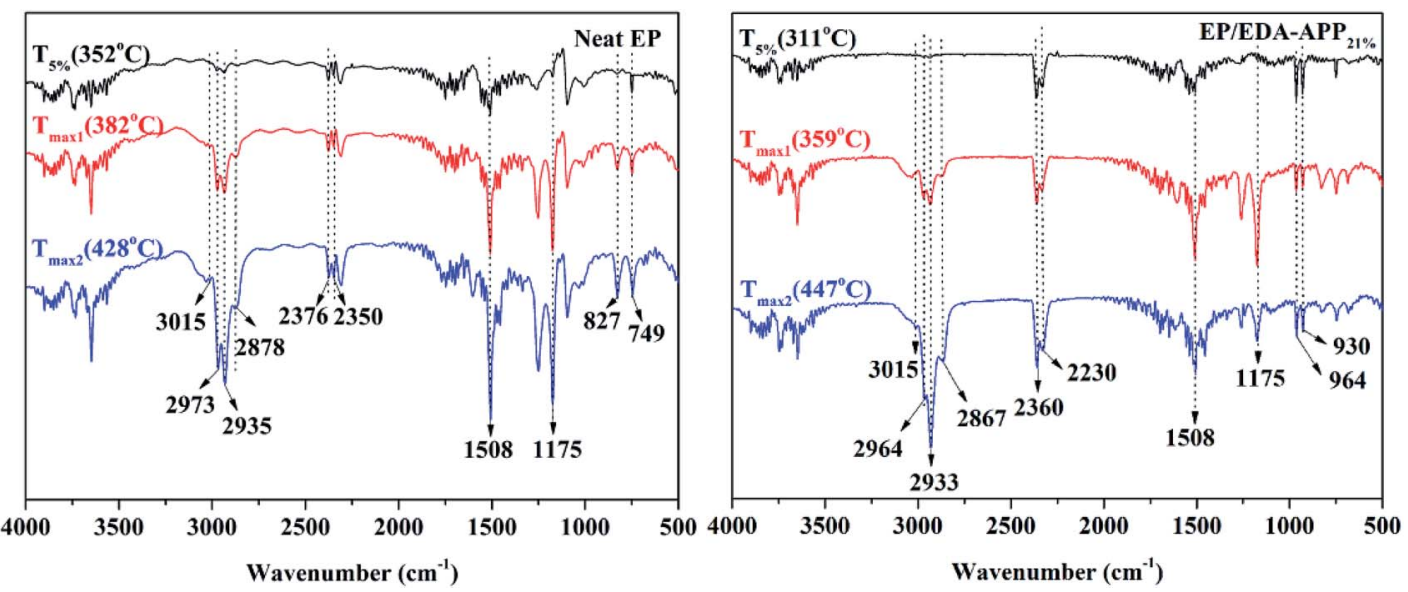

Fig. 8 The FTIR spectra of gaseous phase pyrolysis products of neat EP and EP/EDA-APP $21 \%$ during TGA in a $N_{2}$ atmosphere.
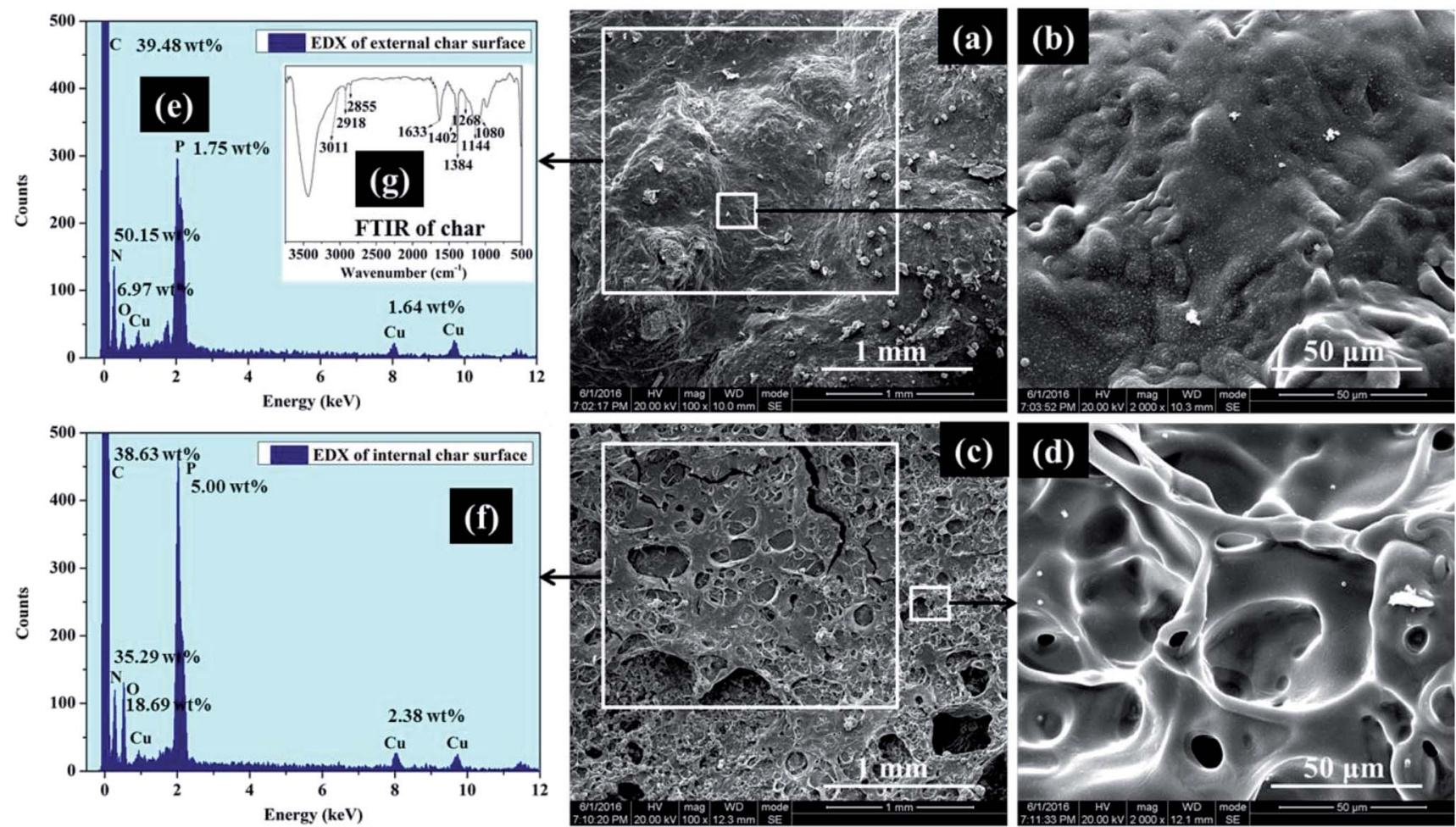

Fig. 9 SEM microphotographs and EDX spectra of external and internal char layers of EP/EDA-APP $19 \% / \mathrm{Cu}_{2} \mathrm{O}_{2}$ after cone calorimeter test.

Table 4 The most possible constituents and the corresponding element contents

\begin{tabular}{|c|c|c|c|c|c|}
\hline Constituents & C (wt\%) & $\mathrm{N}(\mathrm{wt} \%)$ & $\mathrm{O}(\mathrm{wt} \%)$ & P (wt\%) & $\mathrm{Cu}(\mathrm{wt} \%)$ \\
\hline $\mathrm{CuO}$ & & & 0.50 & & 2.01 \\
\hline $\begin{array}{c}\mathrm{O} \\
\sim \mathrm{O}-\stackrel{\mathrm{P}}{\mathrm{P}}-\mathrm{N} m \\
\sim \stackrel{\mathrm{O}}{\mathrm{O}} \mathrm{H}\end{array}$ & & 1.53 & 5.23 & 3.38 & \\
\hline
\end{tabular}

$\mathrm{Ph}-\mathrm{O}-$

$\mathrm{C}=\mathrm{N}, \mathrm{N}=\mathrm{N}$

$\mathrm{C}=\mathrm{C}$, aryl, alkyl

Total

39.06

39.06
41.19

7.1

$\begin{array}{llll}42.72 & 12.83 & 3.38 & 2.01\end{array}$

accelerated the decomposition of EDA-APP and EP. These helped in the improvement of the char formation rate. An early formed intumescent char was a barrier that prevented heat and $\mathrm{O}_{2}$ to transmit into the matrix, hindering the combustible gases feed back into the flame zone and subsequently suppressing the release of smoke and toxic gases. Furthermore, $\mathrm{Cu}_{2} \mathrm{O}$ not only played a role in the oxidation of $\mathrm{CO}$, but also exhibited good synergistic effect with EDA-APP for improving the formation amount, intumescent degree, and compactness of char. 


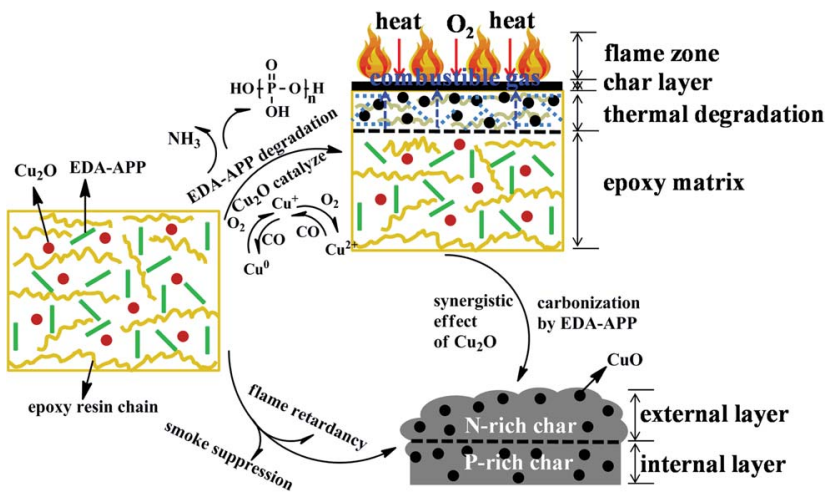

Scheme 2 The possible flame-retardant and smoke-suppressant mechanisms of the EP/EDA-APP/ $\mathrm{Cu}_{2} \mathrm{O}$ composite.

\section{Conclusions}

In conclusion, flame-retardant EP composites were prepared using EDA-APP as an intumescent flame retardant and $\mathrm{Cu}_{2} \mathrm{O}$ as a synergist. LOI and UL-94 test results showed that the minimum demand of EDA-APP was lower than that of APP to obtain UL-94 V-0 rating. The flame-retardant efficiency of the EP/EDA-APP system can be enhanced via the addition of extra $\mathrm{Cu}_{2} \mathrm{O}$. In addition, cone calorimeter and TG-FTIR test results indicated that $\mathrm{Cu}_{2} \mathrm{O}$ had synergistic effect with EDA-APP for suppressing the emission of smoke and toxic gases such as carbon monoxide, hydrocarbons, aromatic compounds, and epoxy derivatives. After analyzing the thermal decomposition behavior of EDA-APP and EP/EDA-APP composites and the composition of their gaseous and condensed pyrolysis products, the flame-retardant and smoke-suppressant mechanisms of $\mathrm{EP} / \mathrm{EDA}-\mathrm{APP} / \mathrm{Cu}_{2} \mathrm{O}$ composite were proposed. It was deduced that EDA-APP was earlier than APP in producing stable char residue, and the formation amount, intumescent degree, and compactness of the char were further improved because of the synergistic effect and catalytic action of $\mathrm{Cu}_{2} \mathrm{O}$.

\section{Acknowledgements}

This work was financially supported by the National Natural Science Foundation of China (21504071), the Opening Project of State Key Laboratory of Polymer Materials Engineering of Sichuan University (sklpme2015-4-34), and the Open Research Subject of Key Laboratory of Automobile High Performance Materials \& Forming Technology in Sichuan Provincial Universities (szjj2015-091 and szjj2016-053).

\section{References}

1 R. Oliwa, M. Heneczkowski, M. Oleksy and H. Galina, Composites, Part B, 2016, 95, 1-8.

2 N. Saba, M. Jawaid, M. T. Paridah and O. Y. Al-othman, Polym. Adv. Technol., 2016, 27, 577-590.

3 D. J. Irvine, J. A. McCluskey and I. M. Robinson, Polym. Degrad. Stab., 2000, 67, 383-396.
4 J. Alongi, Z. Han and S. Bourbigot, Prog. Polym. Sci., 2015, 51, 28-73.

5 H. Q. Qu, W. H. Wu, J. W. Hao, J. H. Sun and J. Z. Xu, J. Macromol. Sci., Phys., 2013, 53, 278-295.

6 W. K. Patrick Lim, M. Mariatti, W. S. Chow and K. T. Mar, Composites, Part B, 2012, 43, 124-128.

7 R. G. Puri and A. S. Khanna,J. Coat. Technol. Res., 2016, 14, 120.

8 Y. Zhang, B. Wang, H. Sheng, B. Yuan, B. Yu, G. Tang, G. Jie, H. Feng, Y. Tao and Y. Hu, RSC Adv., 2016, 6, 85564-85573.

9 L. Boccarusso, L. Carrino, M. Durante, A. Formisano, A. Langella and F. M. C. Minutolo, Composites, Part B, 2016, 89, 117-126.

10 M. Hesami, R. Bagheri and M. Masoomi, Iran. Polym. J., 2014, 23, 469-476.

11 P. F. Chen, F. Zhang, S. X. Li and Y. F. Cheng, J. Appl. Polym. Sci., 2016, 133, 43912-43917.

12 L. Liu, X. Chen and C. Jiao, J. Therm. Anal. Calorim., 2015, 122, 437-447.

13 L. Liu, X. Chen and C. Jiao, Iran. Polym. J., 2015, 24, 337-347. 14 K. Zhang, K. Wu, Y. K. Zhang, H. F. Liu, M. M. Shen and W. Hu, Polym.-Plast. Technol. Eng., 2013, 52, 525-532.

15 S. Zhang, F. Liu, H. Peng, X. Peng, S. Jiang and J. Wang, Ind. Eng. Chem. Res., 2015, 54, 11944-11952.

16 W. Y. Gao, S. J. Wang, F. B. Meng, Y. H. Wang and H. Q. Ma, J. Appl. Polym. Sci., 2016, 133, 43720-43727.

17 W. Gao, S. Wang, H. Ma, Y. Wang and F. Meng, J. Phys. Chem. C, 2015, 119, 28999-29005.

18 Z. Jiang and G. Liu, RSC Adv., 2015, 5, 88445-88455.

19 F. Luo, K. Wu, M. Lu, S. Nie, X. Li and X. Guan, J. Therm. Anal. Calorim., 2015, 120, 1327-1335.

20 H. Qu, W. Wu, J. Hao, C. Wang and J. Xu, Fire Mater., 2014, 38, 312-322.

21 I. Vroman, S. Giraud, F. Salaün and S. Bourbigot, Polym. Degrad. Stab., 2010, 95, 1716-1720.

22 L. Yang, W. Cheng, J. Zhou, H. Li, X. Wang, X. Chen and Z. Zhang, Polym. Degrad. Stab., 2014, 105, 150-159.

23 X. Chen, L. Liu and C. Jiao, Adv. Polym. Technol., 2015, 34, 21516-21524.

24 X. Chen, Y. Jiang and C. Jiao, J. Hazard. Mater., 2014, 266, 114-121.

25 X. He, W. Zhang, D. Yi and R. Yang, J. Fire Sci., 2016, 34, 212225.

26 W. Zhang, X. He, T. Song, Q. Jiao and R. Yang, Polym. Degrad. Stab., 2015, 112, 43-51.

27 B. Schartel, A. Weiß, F. Mohr, M. Kleemeier, A. Hartwig and U. Braun, J. Appl. Polym. Sci., 2010, 118, 1134-1143.

28 M. Jimenez, S. Duquesne and S. Bourbigot, Surf. Coat. Technol., 2006, 201, 979-987.

29 W. P. Lim, M. Mariatti, W. Chow and K. Mar, J. Fire Sci., 2012, 30, 428-436.

30 H. Aziz and F. Ahmad, Prog. Org. Coat., 2016, 101, 431-439. 31 F. Zhang, P. Chen, Y. Wang and S. Li, J. Therm. Anal. Calorim., 2015, 123, 1319-1327.

32 M. J. Chen, Y. C. Lin, X. N. Wang, L. Zhong, Q. L. Li and Z. G. Liu, Ind. Eng. Chem. Res., 2015, 54, 12705-12713. 
33 Z. B. Shao, C. Deng, Y. Tan, M. J. Chen, L. Chen and Y. Z. Wang, ACS Appl. Mater. Interfaces, 2014, 6, 7363-7370.

34 Z. B. Shao, C. Deng, Y. Tan, M. J. Chen, L. Chen and Y. Z. Wang, Polym. Degrad. Stab., 2014, 106, 88-96.

35 Z. B. Shao, C. Deng, Y. Tan, L. Yu, M. J. Chen, L. Chen and Y. Z. Wang, J. Mater. Chem. A, 2014, 2, 13955-13965.

36 Y. Tan, Z. B. Shao, X. F. Chen, J. W. Long, L. Chen and Y. Z. Wang, ACS Appl. Mater. Interfaces, 2015, 7, 17919-17928.

37 Y. Tan, Z. B. Shao, L. X. Yu, J. W. Long, M. Qi, L. Chen and Y. Z. Wang, Polym. Chem., 2016, 7, 3003-3012.

38 Y. Tan, Z. B. Shao, L. X. Yu, Y. J. Xu, W. H. Rao, L. Chen and Y. Z. Wang, Polym. Degrad. Stab., 2016, 131, 62-70.

39 S. F. Liao, C. Deng, S. C. Huang, J. Y. Cao and Y. Z. Wang, Chin. J. Polym. Sci., 2016, 34, 1339-1353.

40 D. Balgude, A. Sabnis and S. K. Ghosh, Prog. Org. Coat., 2017, 104, 250-262.
41 P. Deepak, R. Vignesh Kumar, S. Badrinarayanan, H. Sivaraman and R. Vimal, Mater. Today, 2017, 4, 28412850.

42 S. D. Jiang, Z. M. Bai, G. Tang, Y. Hu and L. Song, Ind. Eng. Chem. Res., 2014, 53, 6708-6717.

43 J. D. McCoy, W. B. Ancipink, C. M. Clarkson, J. M. Kropka, M. C. Celina, N. H. Giron, L. Hailesilassie and N. Fredj, Polymer, 2016, 105, 243-254.

44 P. Müller, M. Morys, A. Sut, C. Jäger, B. Illerhaus and B. Schartel, Polym. Degrad. Stab., 2016, 130, 307-319.

45 W. Zhang, X. Li, H. Fan and R. Yang, Polym. Degrad. Stab., 2012, 97, 2241-2248.

46 G. S. Liu, W. Y. Chen and J. G. Yu, Ind. Eng. Chem. Res., 2010, 49, 12148-12155.

47 M. J. Xu, W. Zhao and B. Li, J. Appl. Polym. Sci., 2014, 131, 41159-41170. 